\title{
Planejamento de Estratégias para o Processo de Inclusão: desafios em questão
}

\author{
Mylene Cristina Santiago' \\ Mônica Pereira dos Santos"
}

'Universidade Federal Fluminense (UFF), Niterói/RJ - Brasil "Universidade Federal do Rio de Janeiro (UFRJ), Rio de Janeiro/RJ - Brasil

RESUMO - Planejamento de Estratégias para o Processo de Inclusão: desafios em questão. Este artigo busca analisar uma experiência de formação continuada de professores atuantes no Atendimento Educacional Especializado no Rio de Janeiro. Nossa argumentação, fundamentada no que denominamos uma perspectiva omnilética, focaliza o planejamento de ações educativas que possibilitem um deslocamento do olhar da deficiência para as potencialidades dos alunos. Metodologicamente, trabalhamos com entrevistas coletivas realizadas em 2012, e com um Ciclo de Formação de 60 horas, ocorrido no ano de 2013. Os resultados apontam para a centralidade do planejamento pedagógico como um processo de investigação/ação, que requer a participação dos atores escolares em situações de reflexão e na transformação da realidade escolar.

Palavras-chave: Formação de Professores. Planejamento. Atendimento Educacional Especializado. Inclusão em Educação. Perspectiva Omnilética.

ABSTRACT - Planning Strategies for Inclusion in Education: challenges for discussion. The present paper aims to analyze the continued education process of teachers who work at the Special Education Sector of Rio de Janeiro state, Brazil. On the basis of what we have named an omnilectical perspective of analysis, we analyze the planning of educational activities that aim to dislocate our standpoints from the disability to the students' potentials. Methodologically, we conducted group interviews during 2012 and a 60-hour Continued Education Cycle in 2013. The results point to the importance of pedagogic planning as an investigation/action process that calls for the participation of school subjects in both reflecting about and transforming school reality.

Keywords: Teacher Education. Planning. Special Education Service. Inclusion in Education. Omnilectical Perspective.

Educação \& Realidade, Porto Alegre, v. 40, n. 2, p. 485-502, abr./jun. 2015. 485 http://dx.doi.org/10.1590/2175-623645248 


\section{Introdução}

O presente trabalho tem o objetivo de relatar o processo de formação no Ciclo de Formação continuada sobre inclusão em educação, tomando como base a premissa de que a inclusão em educação depende, entre outros aspectos, da elaboração de um planejamento pedagógico para o alunado da educação especial que esteja fundamentado em um olhar que desafie os saberes cristalizados e que desloque o foco da deficiência para a potencialidade do sujeito que aprende em uma perspectiva omnilética, a qual apresentaremos ao longo do artigo. Este Ciclo se trata de um desdobramento do Observatório da Educação Especial no Rio de Janeiro (OEERJ), que busca em consonância com o observatório-matriz (Observatório Nacional da Educação Especial-ONEESP), coordenado pela UFSCar, empreender uma avaliação das salas de recursos multifuncionais (SRM).

No âmbito do Estado do Rio de Janeiro, esta pesquisa envolve professores e gestores que atuam no Atendimento Educacional Especializado em quatro municípios: Niterói, Nova Iguaçu, Petrópolis e Rio de Janeiro: e conta com a participação de pesquisadores das Universidades Federais: do Rio de Janeiro (UFRJ), Fluminense (UFF), Rural Rio de Janeiro (UFRRJ) e da Universidade Estadual do Rio de Janeiro (UERJ).

A Política Nacional de Educação Especial na Perspectiva da Educação Inclusiva (Brasil, 2007) define que a educação especial é uma modalidade de ensino que perpassa todos os níveis, etapas e modalidades, realiza o atendimento educacional especializado, disponibiliza os recursos e serviços e orienta quanto à sua utilização no processo de ensino e aprendizagem nas turmas comuns do ensino regular. Em síntese, a mencionada política recomenda a implementação de políticas públicas para que alunos com deficiência (física, sensoriais e intelectuais), com transtornos globais do desenvolvimento e com altas habilidades/superdotação tenham garantido o acesso, a participação e o aprendizado nas escolas comuns.

De acordo com as Diretrizes da referida política, o atendimento educacional especializado tem como função identificar, elaborar e organizar recursos pedagógicos e de acessibilidade que eliminem as barreiras para a plena participação dos estudantes, considerando suas necessidades específicas. As atividades desenvolvidas no atendimento educacional especializado diferenciam-se daquelas realizadas na sala de aula comum, não sendo substitutivas à escolarização, ou seja, esse atendimento complementa e/ou suplementa a formação dos estudantes com vistas à autonomia dentro e fora da escola.

No decorrer da pesquisa, diferentes etapas foram realizadas, entre os anos de 2012 e 2013, e com uma população de professores de Atendimento Educacional Especializado (AEE) dos quatro municípios participantes. Tais etapas consistiram em: estudo preliminar sobre os 
dados demográficos e administrativos; entrevistas realizadas com os gestores de Educação Especial dos quatro municípios; realização de entrevistas coletivas sobre os eixos temáticos: formação de professores para inclusão escolar; avaliação do estudante com necessidades educacionais especiais; organização do ensino nas Salas de Recursos Multifuncionais (SRM) e classes comuns; e, realização do Ciclo de Formação de Professores para a Inclusão, que se trata de um desdobramento das reflexões suscitadas pelos professores durante as entrevistas coletivas. Ao longo dos dois anos, tivemos a oportunidade de colher dados de cerca de 100 professores de Atendimento Educacional Especializado (AEE) e de alguns membros das equipes gestoras da Educação Especial dos quatro municípios participantes.

A fim de compreendermos as culturas, políticas e práticas de inclusão (Booth; Aisncow, 2011) que vêm sendo desenvolvidas no cotidiano das escolas que possuem salas de recursos multifuncionais, nos deteremos, neste trabalho, no terceiro eixo temático, que se refere à organização do ensino nas SRM e classes comuns, assim como no processo de formação desenvolvido no referido ciclo de formação continuada.

Nossa argumentação terá como foco o planejamento de ações educativas que visem eliminar barreiras à participação e à aprendizagem dos alunos público alvo da educação especial. Para isso, centralizaremos nossos argumentos na necessidade do planejamento e da intencionalidade das ações educativas e na importância do deslocamento do olhar da deficiência para as potencialidades dos alunos. Nossas análises estarão fundamentadas na perspectiva omnilética (Santos, 2013), na qual concebemos que o processo de inclusão em educação precisa ser compreendido de uma forma totalizante, tendo em vista que abrange de modo tanto complexo quanto dialético, o desenvolvimento de culturas, políticas e práticas de inclusão entre e pelos atores e instituições educacionais.

A perspectiva omnilética parte do princípio de que todo e qualquer fenômeno humano e social pode ser compreendido (e desafiado) a partir do reconhecimento das relações, ao mesmo tempo dialéticas e complexas, das três grandes dimensões nas quais manifestamos nossa existência pessoal, coletiva e institucional: a das culturas, políticas e práticas. A dimensão das culturas refere-se a valores que temos e justificativas que damos para explicar o mundo. A das políticas faz referência não apenas às conhecidas políticas públicas, como também abrange toda intenção expressa que tem por objetivo orientar e organizar ações. Políticas refletem decisões tomadas e geralmente implicam em planos de ação. A das práticas refere-se às práticas e ações pessoais e sociais propriamente ditas, a o quê e como fazemos as coisas.

Deste modo, tudo o que a humanidade é e faz, seja no plano individual, seja nos planos coletivos, se expressa cultural, política e praticamente, de formas nem sempre harmoniosa ou desprovida de conflitos. 
Pelo contrário, o movimento humano de busca (práticas) pela solução (políticas) de conflitos e problemas (culturas) é sempre dialético e complexo, posto que incessante, contraditório (dialética) e revelador exponencial (complexidade) de novas culturas, políticas e práticas.

\title{
O Planejamento e a Intencionalidade do Ato Educativo: articulações na escola
}

Para compreender o contexto das salas de recursos multifuncionais, consideramos a importância de situar esse espaço sob uma perspectiva didática omnilética, com a função político-pedagógica de concretizar objetivos e modos de intervenção em situações específicas de ensino-aprendizagem, que dado seu caráter intencional, solicita planejamento. De acordo com Franco,

\begin{abstract}
A prática docente é uma prática pedagógica quando esta se insere na intencionalidade prevista para sua ação. Assim, enfatizo que um professor que sabe qual é o sentido de sua aula frente à formação do aluno, que sabe como sua aula integra e expande a formação desse aluno, que tem a consciência do significado de sua ação, esse professor tem uma atuação pedagógica diferenciada: ele dialoga com a necessidade do estudante, insiste em sua aprendizagem, acompanha seu interesse, faz questão de produzir aquele aprendizado, acredita que este aprendizado será importante para o aluno (Franco, 2012, p. 178).
\end{abstract}

As atividades (dimensão das práticas) desenvolvidas no atendimento educacional especializado são práticas pedagógicas intencionais, que precisam estar circunscritas (políticas) em valores (culturas) como os descritos acima. Os objetivos do atendimento educacional especializado, descritos no Decreto 7611/11, são: prover condições de acesso, participação e aprendizagem no ensino regular e garantir serviços de apoio especializados de acordo com as necessidades individuais dos estudantes; garantir a transversalidade das ações da educação especial no ensino regular; fomentar o desenvolvimento de recursos didáticos e pedagógicos que eliminem as barreiras do processo de ensino e aprendizagem; e assegurar condições para a continuidade de estudos nos demais níveis, modalidades e etapas de ensino. Ao refletirem sobre a função do AEE, as professoras expressam que:

O objetivo da sala de recursos é complementar mesmo, não é? Não é outro currículo, é um atendimento educacional especializado que venha consolidar, fortalecer aquele conteúdo que o professor está dando, que a criança está tendo na sala comum. É lógico que nós temos os casos mais acentuados, de comprometimento mais acentuado, todos esses o professor tem formação para fazer o plano educacional individualizado, para criar o PEI (Plano de Ensino Individualizado) desses alunos, isto é acompanhado pela família, pela escola, pelos professores, ou seja, há um conhecimento 
geral desse trabalho. O objetivo do AEE na sala de recurso é isso, é oferecer o atendimento complementar e suplementar quando se tratam das crianças com altas habilidades ou superdotação (professora N).

Para atender os objetivos e funções traçados para o AEE, os professores e a escola como um todo precisam organizar e planejar (políticas) esse espaço de forma coletiva. Estas ações, por sua vez, implicam em uma constante revisita (práticas) aos objetivos e fundamentos (culturas) daquilo que se entende e se quer (culturas) com a educação. Nas reflexões das professoras essa necessidade de planejamento e organização (políticas) surge de forma recorrente:

Começamos a fazer a primeira entrevista, o primeiro contato com os responsáveis, onde há uma entrevista e logo depois começamos o atendimento, é feito todo um planejamento para se trabalhar com aquele aluno. Depois de já identificadas as suas necessidades, a gente uma vez por mês tem um encontro com a equipe, onde colocamos as nossas dificuldades e algumas vezes estudamos sobre casos de alguns alunos para que outras colegas compartilhem com a gente aquela experiência [...] a gente faz um acompanhamento e a gente observa o aluno em sala de aula, conversa com o coordenador, vai buscando informações e vê como o aluno interage com a turma, com a escola, até com os docentes e tudo mais; como é esse aluno no espaço onde ele passa maior parte do tempo? E dessa forma, também, a gente pode orientar o professor, levando material para trabalhar com esse aluno em sala de aula (professora G).

Do acolhimento ao atendimento do aluno no AEE, a professora acima expressa a necessidade de uma ação contínua e integrada entre os atores escolares, em que entram em jogo suas culturas, políticas e práticas. Este jogo é sempre complexo e dialético: seus valores e crenças (culturas), sua forma de organizar seus pensamentos, saberes e ações (políticas), assim como as ações que decidem adotar (práticas) nem sempre são os mesmos. Mesmo quando são os mesmos, não há garantia de que o sejam sempre e consistentemente, o que implica reconhecer, justamente, que por trás do que se vê há mais para se (re)ver (dialética), e que cada novo exercício desta (re)visão provoca múltiplas outras novas situações, cada uma com novas e infinitas possibilidades de análise e transformação (complexidade). Com o objetivo de propor a participação e a aprendizagem do aluno há uma série de ações descritas que visam, sobretudo, auxiliar o professor na tomada de decisões e nas práticas mais favoráveis à situação de cada aluno. Na transcrição posterior, evidenciamos situações que exigem condutas diferenciadas, aparentemente, em função da condição do aluno a ser atendido,

Para aqueles alunos que têm comprometimento severo, há um planejamento educacional individualizado, a gente não tem Planejamento Educacional Individualizado para todo e qualquer aluno não, a gente tem um PEI para os severamente comprometidos. Aos outros alunos o planejamento é totalmente inserido dentro da proposta curricular do plano de curso daquele grupo (professora $\mathrm{N}$ ). 
No entanto, quando olhamos omnileticamente para o discurso acima, percebemos que há uma série de fatores atuando, visíveis e invisíveis (dialética), que podem levar, exponencialmente, a variadas novas proposições e mudanças (complexidade). Isto porque, embutidos na fala acima, podemos identificar, de imediato, vários aspectos não externalizados, mas já presentes nas culturas, políticas e práticas da professora - e, provavelmente, perceptíveis também nas práticas de sua instituição. Por exemplo: implícito na expressão comprometimento severo, já está uma percepção própria e valorativa (culturas) do que seja comprometimento e severo, que apontam para uma ação diferenciada (práticas), que é o Plano Educacional Individualizado (PEI). Por outro lado, esta mesma ação está contemplada nas diretrizes nacionais e institucionais (políticas), respaldando, ainda que com todas as suas contradições (pode não haver professores, o processo pode ser longo e demorado, pode haver discordância quanto ao PEI entre os profissionais que o executarão etc.) - aspecto dialético - as práticas, ao mesmo tempo em que apontando para outras necessidades de se perceber e adotar novas configurações culturais, políticas e práticas (complexidade).

Em relação ao planejamento, é inegável sua importância, no entanto, cada realidade possui propostas e situações diferentes, que respondem aos seus contextos específicos, conforme verificamos nas seguintes transcrições:

O planejamento é feito com o professor da sala de ensino regular e ele tem o planejamento da turma dele e junto com a professora do AEE, é feito um plano de ação para aquele aluno que está inteirado. Então junto com professor da turma regular, a gente faz um plano do que a gente quer atingir naquele bimestre para aquele aluno, quais são os focos que aquele aluno tem que atingir naquele bimestre. Então o planejamento dele é dentro daquele planejamento que é feito para a turma inteira, só que adaptado à maneira que pegue os focos mais objetivos para aquele aluno ser atingido (professora J).

Eu faço um planejamento anual individualizado para cada aluno, mas não em parceria com nenhum outro professor, por que acaba não havendo esse encontro. Então, o trabalho que eu realizo na sala de recurso não tem diretamente um vínculo com a sala regular. Eu não tenho que acompanhar o que o professor da sala regular está dando na turma para esse meu aluno na sala de recurso. Eu, no caso, faço uma avaliação desse aluno, vejo quais são as necessidades que precisam ser trabalhadas com aquele aluno e faço o planejamento em cima daquilo que eu observo do aluno e os planejamentos são encaminhados para a equipe que compartilha com o professor. Em alguns momentos eu acabo ficando na escola (eu trabalho no turno da manhã) para poder fazer uma troca com o professor (professora X).

As nossas salas de recursos funcionam no mesmo turno, eu continuo dizendo isso em Niterói nós não conseguimos fazer contra turno. Não conseguimos por uma questão muito familiar. Em primeiríssimo lugar os familiares não têm condições de buscar a criança, ônibus... Não têm. 
Então, a gente faz um planejamento com o professor da sala de aula comum, semanal, todos os professores têm hora especial de planejamento (professora N).

Recorrentemente defendemos a importância do planejamento coletivo envolvendo o professor do AEE e da sala de aula comum. Todavia, essa realidade não se confirma uniformemente nos contextos dos municípios investigados, em função das distintas sistematizações políticas do AEE e das diferentes realidades municipais, das famílias envolvidas, dos outros atores sociais envolvidos (professores, alunos, gestores), e assim sucessivamente, em um movimento totalizante, complexo e perpassado por várias possibilidades de mudanças culturais, políticas e práticas e, portanto, omnilético. A título de exemplo, mais uma vez, lembramos, conforme evidenciado em uma das transcrições acima, o caso de um município que não oferece o AEE no contra turno escolar (a prática não corresponde à política), como é recomendado pela política nacional. Em contrapartida, o mesmo município consegue promover momentos de planejamento coletivo (o que pressupõe uma cultura relativamente bem consolidada de colaboração), envolvendo professor de AEE e de sala comum (gerando uma prática diferenciada daquela oficializada, mas, nem por isso, necessariamente ineficaz). Desse modo, podemos demonstrar que nem sempre as intenções e orientações legislativas conseguem ser implementadas no dia a dia institucional conforme explicitado no texto, o que é absolutamente compreensível quando se percebe o quadro omnileticamente. No contexto da prática, as leis e orientações são redefinidas para que possam ser viabilizadas em cada realidade municipal ou até mesmo, em cada unidade de ensino. Isto é movimento omnilético, porque altera culturas, políticas e práticas, de formas variadas perceptíveis ou veladas (dialética) e exponenciais em um sentido auto-organizativo (complexidade).

\section{Da Deficiência às Potencialidades: desenvolvendo novos olhares}

Em nossa leitura omnilética do mundo, defendemos, portanto, a necessidade de se adquirir novos olhares e concepções sobre os alunos como um passo importante para a elaboração de um planejamento que possa ampliar suas possibilidades de aprendizagem e de participação no espaço escolar. Para justificar essa afirmação, recorremos ao chamado efeito pigmaleão na escola, que se trata de um estudo realizado pelos pesquisadores Rosenthal e Jacobson (1968), que consideram a existência de uma relação entre as expectativas do professor e a probabilidade de progressos significativos entre os alunos. Nesse estudo se desenvolve a hipótese de que a dinâmica das profecias autorrealizáveis podem interferir na vida e trajetória escolar dos alunos. De acordo com Trouillouc e Sarrazin: 
Planejamento de Estratégias para o Processo de Inclusão

Geralmente existem dois tipos de estudos sobre o efeito Pigmaleão. O primeiro, assim como a de Rosenthal e Jacobson (1968) consistiu em induzir expectativas entre os professores, fornecendo informações falsas sobre estudantes (como resultados falsificados nos testes). O segundo tipo, estudos semelhantes aos de Rist (1970), usou as expectativas naturalmente estabelecidas pelos professores em suas salas de aula. Em todos estes estudos, a profecia autorrealizadora foi demonstrada quando uma crença ou expectativa de um professor em relação ao aluno modificou a atitude do primeiro em relação ao segundo, resultando na tendência de confirmar as crenças do professor (Trouillouc; Sarrazin, 2003, p. 93).

Entre os alunos particularmente vulneráveis às expectativas dos professores, os autores destacam certas características sociodemográficas como idade, origem étnica, social e trajetória escolar. Não há menção quanto aos alunos da educação especial em tais estudos, entretanto, sinalizamos que expectativas positivas em relação à aprendizagem e participação dos alunos com deficiência podem fazer a diferença em suas trajetórias escolares. Desse modo, consideramos a importância de efetuarmos um deslocamento de olhar da deficiência para a potencialidade de nossos alunos atendidos nas salas de recursos multifuncionais.

Paralelo a esse processo, e tendo em vista mesmo uma análise Omnilética (que considera a multiplicidade de fatores envolvidos nos fenômenos sociais em termos culturais, políticos, práticos, dialéticos e complexos) não se pode olvidar de empreender esforços em outras direções. Uma delas é a da formação continuada para os professores, pois, nos é sinalizado também, que a crença do professor em sua capacidade de ensinar pode favorecer a aquisição de resultados específicos e maior qualidade no processo de ensino (Trouillouc; Sarrazin, 2003). O processo formativo requer reflexão sobre a própria prática e sensibilidade com as diferenças, conforme nos orienta Arroyo:

A chegada de outras crianças e adolescentes às salas de aula obriga os professores que têm sensibilidade de vê-los, a criarem novas autoimagens de sua condição docente. Criam outros sentidos para as salas de aula. Dessas infâncias e adolescências vêm demandas de outros significados para as escolas, para a docência e para o próprio currículo e seus ordenamentos e conhecimentos (Arroyo, 2011, p. 223).

A citação de Arroyo nos convida a refletir sobre a diversidade com a qual lidamos no cotidiano escolar e sobre a necessidade de adotarmos olhares e posturas sensíveis às diferenças de nosso alunado, o que não significa a oferta de oportunidades iguais, uniformes e homogêneas, que frequentemente representa a manutenção de processos excludentes, através da cultura da indiferença à diferença (Bourdieu; Passeron, 2008). 
O processo de reconhecimento das diferenças e dos novos significados nos impele a assumir um papel não somente pedagógico, mas, sobretudo, político, pois oferecer condições de participação e produzir significados e saberes que respondam às necessidades de todos, transcende uma questão técnica e nos desafia a assumir a educação como processo de luta na garantia de direitos e construção de um mundo mais justo, civilizado, cidadão. Quando falamos do direito à autonomia e do direito de aprender, nos referimos ao nosso papel político e pedagógico de oferecer oportunidades diferenciadas de participação, conforme a necessidade específica de cada um e essa tem sido a principal função do professor de AEE identificada em nossos estudos e reflexões.

Estes papéis impõem grandes desafios aos educadores, em especial para o professor de AEE, que no nosso entender pode se tornar o grande desencadeador de questões e articulações do desenvolvimento de culturas, políticas e práticas de inclusão/exclusão na escola, desvelando e revelando, dialeticamente, as relações contraditórias entre os atores que circulam, atuam e existem naquelas dimensões na instituição escolar, como também considerando toda a complexidade de efeitos e imbricações que estas relações promovem no dia a dia, surtindo novos mecanismos de inclusão e de exclusão.

Ressaltamos que não temos a pretensão de hierarquizar os desafios que pretendemos problematizar e que elencamos a identificação e superação de barreiras à participação e à aprendizagem dos alunos no cotidiano escolar como o primeiro desafio porque nos remetem à autoavaliação e reflexão de nossos valores, concepções e práticas. Qualquer processo de mudança implica na avaliação de nossas condições atuais para que possamos planejar o que precisa ser transformado e pensar quem são os atores envolvidos nesse processo. Implica, adicionalmente, não termos a ilusão de que as transformações curem os problemas, contradições e conflitos presentes neste dia a dia, mas que nos tornem, como atores sociais, conscientes dos mesmos, mobilizando-nos a ser mais proativos e a tomarmos decisões minimamente reflexivas e mais informadas.

O segundo desafio seria assumir as diferenças entre os alunos com peculiaridades, rompendo com a ideia de que as mesmas são problemas que precisam ser corrigidos ou normalizados. A proposta do AEE é oferecer apoio, de modo que o aluno consiga participar e contribuir com o processo de ensino-aprendizagem por meio de suas singularidades. Esse desafio está totalmente associado com o próximo, que se trata de aprender a dialogar com as particularidades do sujeito, ou seja, é através do contato, e acima de tudo do diálogo, com o aluno que aprendemos sobre ele e que podemos investigar e oferecer propostas significativas para seu desenvolvimento e participação. Esse desafio nos questiona sobre como lidamos e o que para nós representa a diferença do outro. Como afirmado anteriormente, não são desafios específicos para o professor de AEE, mas são desafios centrais em sua prática cotidiana ao 
Planejamento de Estratégias para o Processo de Inclusão

atender alunos e orientar professores em relação às especificidades do processo educativo.

Outro importante desafio é superar barreiras relativas à homogeneização curricular, aos processos avaliativos que selecionam e classificam os alunos, em uma realidade que, dialeticamente, ao mesmo tempo em que defende práticas educacionais mais justas e democráticas, autoritariamente impossibilita a consideração dos tempos e ritmos individuais. Definitivamente, essa não é uma atribuição exclusiva do professor de AEE, esse processo envolve todos os atores da escola, porque desenvolvem, conscientemente ou não, culturas, políticas e práticas que vão regendo o cotidiano escolar. Entretanto, o professor de AEE pode ser um importante catalisador institucional das diferentes culturas, políticas e práticas dialética e complexamente ali presentes, o que lhe coloca em um lugar de especial sensibilidade para questionar, dialogar, propor e convocar a um processo de reflexão sobre o cotidiano e suas exclusões.

O desenvolvimento de culturas de inclusão envolve a adoção de valores e concepções que impliquem expectativas positivas em relação à participação e ao desenvolvimento de todos os alunos, o que em certa medida impõe a problematização das consequências sociais das não aprendizagens e dos fatores determinantes que facilitam a vida escolar de alguns alunos e impõe barreiras de sucesso escolar a outros.

O planejamento diante das dimensões de inclusão assume um caráter complexo que envolve ação reflexiva e contínua, ou seja, é um ato permeado por processo de avaliação e revisão em que nos interrogamos: Estou no caminho certo? O aluno está aprendendo? Eu estou possibilitando participação?

Ato decisório (políticas), político (políticas) e ético (culturas), porque o processo exige reflexão (práticas) sobre a nossa função social (políticas e práticas), o que precisamos realizar para tentar transformar (práticas) a escola em um espaço mais inclusivo. O espaço do AEE é potencialmente relevante para problematizar e identificar (práticas) as barreiras de exclusão presentes na escola. Esse fato torna o professor de AEE um ator importante nas articulações políticas (políticas e práticas), como por exemplo, na elaboração (práticas) do projeto político-pedagógico - PPP - (políticas) da escola, no sentido de provocar questões e visibilizar tensões (práticas). Salientamos que a elaboração do PPP é contínua e que esse instrumento precisa ser construído (práticas) e avaliado (culturas) sistematicamente, assim como nossa prática, pois caso contrário, se torna um documento burocrático e descontextualizado da realidade da escola. Se a escola é viva, se nossas práticas mudam diariamente, o PPP (políticas) precisa registrar e atualizar tais mudanças com a mesma frequência em que ocorrem. Para Pinto (2012), o PPP é o instrumento pelo qual a escola pode garantir o exercício de sua autonomia e consolidar a cultura escolar local. 
O planejamento envolve também ideias, valores, crenças e projetos da própria escola, interferindo diretamente nas culturas, políticas e práticas, ao nos exigir escolhas, opções metodológicas e teóricas. Nessa perspectiva o planejamento transcende (dialética e complexidade) o espaço da sala de aula, favorecendo possibilidades coletivas para que os atores escolares compartilhem uma filosofia de inclusão e assumam identidade institucional.

Todos os desafios destacados envolvem processo de investigação/ ação, que requer a participação dos atores escolares em situações de reflexão cooperativa e na transformação da realidade da escola, ou seja, no planejamento, no desenvolvimento e na avaliação das estratégias de mudanças e compreensão crítica da própria prática pedagógica e de seus desdobramentos no processo de participação e de aprendizagem dos alunos.

\section{Compreendendo Omnileticamente Inclusão em Educação: novos desafios em questão}

Partindo do pressuposto de que atuar pedagogicamente em uma perspectiva omnilética de inclusão em educação, a qual envolve pensar a diferença, dialética e complexamente, em um campo cultural, político e prático em permanente interação e em mútua influência, requer posturas e adoção de valores que construam práticas que valorizem a dignidade humana e promovam relações mais éticas, ou seja, o processo de inclusão em educação redefine valores (culturas) e orienta (políticas) novas ações (práticas) em todo o contexto educacional, a todo momento, e sempre de forma relativamente imprevisível quanto aos seus efeitos. Isto nos impulsiona a desvelar cada nova entrelinha que se apresenta na medida em que as coisas acontecem e nos coloca perante o grande desafio da complexidade de lidar com o princípio da incerteza (Morin, 2006), ao mesmo tempo em que apostando na capacidade exponencial de auto-organização e recriação (idem) dos seres humanos e instituições. De acordo com Drago (2013), um processo de inclusão bem planejado entende que existem barreiras que precisam ser transpostas, que métodos de ensino precisam ser revistos e que o ensino coletivo é um caminho interessante para o desenvolvimento de relações que promovam a aprendizagem e participação de todos.

A despeito de nossa concordância com o autor em reconhecer a relevância destes aspectos, frisamos a importância de não nos iludirmos achando que melhorias conseguidas a cada passo da luta sejam eternas ou venham para ficar, tendo em vista, justamente, este movimento omnilético que tanto nos caracteriza: valores e crenças (culturas) influenciando, harmônica e conflituosamente (dialética), bem como reconhecendo a infinidade de movimentos que exponencialmente criam mais e outros movimentos (complexidade), as intenções e decisões (políticas), que por sua vez influenciam nossas ações efetivas 
Planejamento de Estratégias para o Processo de Inclusão

(práticas). Os caminhos contrários (práticas influenciando, dialética e complexamente, políticas e culturas, e políticas influenciando, dialética e complexamente, práticas e culturas) são, igualmente, verdadeiros e válidos nesta perspectiva.

Assim, durante nossa pesquisa foram evidenciados novos desafios surgidos a partir da identificação de barreiras a serem transpostas no cotidiano das salas de recursos multifuncionais e/ou na escola como um todo. Durante as entrevistas e situações de formação os professores de AEE declararam um sentimento de destituição de conhecimentos necessários para uma prática de qualidade, nas suas palavras:

A sala de recursos veio para que tenha um professor super-herói, não é? Que ele seja especialista em tudo, que ele saiba de todas as deficiências, que ele entenda de tudo um pouco. Esse é o perfil que eu vejo que é colocado hoje para professor da sala de recursos, ele tem que ser multi, como diz o nome, é multifuncional (professora R).

A escolarização deveria acontecer para que esse aluno com necessidade educacional especial tivesse os mesmos direitos e exercessem cidadania como qualquer outro cidadão, mas infelizmente isso ainda não acontece da maneira que deveria acontecer. [...] Pelo menos na minha escola ainda não funciona da forma que deveria funcionar porque o atendimento educacional especializado seria justamente para poder estar suprindo, eliminando as barreiras que esse aluno encontra para adaptar-se em uma escola comum, barreiras essas de acesso para o cadeirante, de comunicação do surdo que não tem a primeira língua [...] eu tenho casos lá na escola e o AEE na realidade não tem este preparo para atender todas as necessidades, as demandas que surgem na escola eu não tenho a (formação em) LIBRAS e eu tenho um aluno que é surdo (professora C).

A exigência de preparação como formação (políticas), evidencia uma crença (culturas) de que a formação, enquanto movimento prévio e predominantemente teórico possibilita a aquisição de habilidades para lidar (práticas) com determinadas tipologias de aluno. Entretanto (dialética e complexidade), compreendemos que lidar com a questão da deficiência implica em enfrentar (práticas) as próprias concepções de normalidade (culturas) e as próprias expectativas (políticas). Desse modo, não há como obter uma consistente formação teórica alijada do contato com as pessoas e suas histórias. As mudanças concretas (pedagógicas e estruturais) ocorrem de forma dinâmica, dialética e complexa através das interações no espaço escolar (Anjos; Silva; Melo, 2013). O relato abaixo sugere que a formação/atribuição do professor para promover o processo de inclusão é um desafio no cotidiano escolar:

[...] A gente recebe um professor de apoio hoje, 2012, que já tem toda essa trajetória [práticas], então recebe um professor de apoio que vai trabalhar com essa criança, vamos dizer hoje autista e tem hiperatividade e tem uma deficiência mental, então mesmo que o professor já vindo com alguma preparação na área de educação especial [culturas e práticas] tem uma dificuldade de trabalhar [culturas, políticas e práticas]. A gente 
precisa [culturas] estudar [práticas], a gente precisa [culturas] compartilhar os conhecimentos [práticas], a gente precisa [culturas] trocar [práticas], a gente precisa [culturas] conversar com a família [práticas], a gente precisa [culturas] estar na escola [práticas], acompanhando [políticas e práticas] como vai ser o processo de inclusão. [...] A escola e mesmo o professor precisam entender [culturas] que professor não é um cuidador [culturas e políticas], o trabalho que precisa ser desenvolvido é um trabalho pedagógico [culturas e políticas] (professora $\mathrm{H}$ ).

Como se percebe pelo exercício omnilético exercido com o excerto discursivo acima, culturas, políticas e práticas estão incessantemente em relação e movimento dialético e complexo, porque apontam, ao mesmo tempo, desejos possíveis e não imediatamente possíveis; ações corretas e incorretas, que se complexificam (ampliam, auto-organizam e auto-desorganizam) a cada nova mirada omnilética.

Além das dificuldades destacadas para se trabalhar com peculiaridades dos alunos, evidenciamos que a inclusão requer quebras de cristalizações educacionais e reorganização do sistema educacional para que se efetivem ambientes dinâmicos e envolventes para estimular todos os alunos, conforme evidencia a seguinte transcrição:

Ano passado nós fomos fazer visita na escola de um desses alunos para poder ver o quê que está acontecendo, ele não caminha, é uma dificuldade muito grande para a escola de trabalhar com ele. Então nessa visita fomos conversar com o professor, com a orientação, com a direção, com todo mundo para até mostrar como é que a gente faz o trabalho, como é que a gente trabalha com ele na sala de recursos. [...] O aluno estava no $5^{\circ}$ ano, do $4^{\circ}$ para o $5^{\circ}$ ano, não estava nem alfabetizado, tem Síndrome de Down e tinha um quadro cheio de coisas para copiar [...] você pega o caderno e está cheio de bichinhos, você vê que a socialização está muito boa, mas a questão do trabalho propriamente dito em relação à alfabetização dele, não. Estava totalmente esquecida (professora N).

Outro aspecto que merece nossa atenção diz respeito às condições de trabalho e reconhecimento do profissional do AEE, conforme nos explica a transcrição abaixo:

Não temos um tempo garantido na escola para planejamentos e produções, o planejamento sou eu quem faz, em casa entre um espaço e outro. Estou desabafando. Ninguém nos supervisiona. E tem mais, recebemos menos do que o professor de sala de aula comum. As pessoas estão deixando as salas de recursos, porque não recebem da mesma forma. Eu também pensei em deixar a sala de recursos (professora $\mathrm{H}$ ).

Como dito anteriormente, as realidades educacionais no Estado do Rio de Janeiro são múltiplas e requerem atenção política e pedagógica no que se refere ao atendimento às especificidades dos alunos e à oferta de formação aos professores quanto às linguagens e códigos que precisam conhecer, conforme expressa a transcrição abaixo sobre os desafios para se trabalhar com alunos com surdez: 
Planejamento de Estratégias para o Processo de Inclusão

Um limite maior que eu vejo além do contato com o professor regente é no caso da surdez que eu acho que a sala de recursos não dá conta de toda a necessidade do aluno surdo. Se a gente fizer como [...] é proposto pelo MEC, não é possível, eles não adquirem língua desta maneira. As estratégias não atendem às necessidades, eles ficam excluídos nas salas de aula se for assim, eles em sala de aula regular e o que o MEC propõe não é possível de ser realizado pela sala de recursos, porque o surdo não pode ir para sala de recursos para ter três atendimentos diferentes [...] eles (alunos surdos) acabam formando um grupo de turma bilíngue na sala de recursos. [...] E não atende a nenhuma das três propostas que estão previstas pelo MEC (professora R).

De fato, a publicação atual adotada pelo Ministério da Educação (MEC) sobre o AEE e o trabalho com surdos sugere a adoção de três "momentos didáticos" (Damázio, 2007, p. 25): o Atendimento Educacional Especializado em Libras $^{l}$ na Escola Comum, o Atendimento Educacional Especializado para o ensino da Língua Portuguesa e o Atendimento Educacional Especializado para o ensino de Libras (grifos nossos).

A ideia do momento AEE em LIBRAS é a de se antecipar aos conteúdos que serão trabalhados na sala regular, ensinando-os na SRM antes da aula propriamente dita em que tais conteúdos serão dados. De acordo com Amorim,

Nesse contexto, a proposta da SRM para o ensino em LIBRAS objetiva proporcionar a este alunado o acesso a informações sociais e conceitos curriculares que facilite sua compreensão do conteúdo abordado na classe comum e participação ativa na sala de aula. Para tanto, exige-se que o professor da SRM seja um profissional proficiente em Língua de Sinais - Professor (a) Bilíngue, para que dessa forma, haja uma interação direta entre professor e aluno sem que seja necessária a presença do intérprete (Amorim, 2011, s/p).

Já no que tange ao AEE para o ensino da Língua Portuguesa, a ideia deste momento é desenvolver a competência gramatical e linguística, bem como a textual, para que os surdos sejam capazes de gerar sequências linguísticas bem formadas, visando, particularmente, o aprimoramento do português escrito. Um dos requisitos para que tal aconteça, segundo Amorim (idem), é de que "[...] o espaço da SRM seja rico em diversidades textuais que garantam a familiaridade do aluno surdo com materiais impressos, buscando a priori significá-los através da Língua de Sinais" (Amorim, 2011, s/p).

No que diz respeito ao terceiro momento, AEE para o ensino de LIBRAS, Amorim (idem), mais uma vez, nos diz que:

O AEE para o ensino DA LIBRAS objetiva em primeiro lugar garantir que o aluno tenha acesso a uma língua, uma vez que muitos surdos não têm. Enriquecer a aprendizagem, favorecendo assim o conhecimento e a aquisição, principalmente de termos científicos (Amorim, 2011, s/p). 
Pelo exposto, percebemos que a queixa da professora tem certo sentido. Os três objetivos diferenciados (facilitar o entendimento das aulas comuns, no momento AEE EM LIBRAS; ensinar a língua, no momento AEE DE LIBRAS; e aprimorar a construção e entendimento textual e da escrita em português, no momento AEE PARA A LÍNGUA PORTUGUESA) requerem medidas que, pelo que temos visto em nossa pesquisa, nem sempre podem ser adotadas na realidade escolar. Em primeiro lugar, porque, como todos estes atendimentos são em contra turno, muitas famílias não conseguem retornar por impedimentos de trabalho ou financeiros. Em segundo lugar, porque dificilmente um professor de AEE, apenas, será capaz de ensinar, com a mesma fluência, em Libras, a Libras e a Língua Portuguesa numa metodologia de segunda língua.

Finalmente, chamamos atenção para a importância das relações coletivas e do entendimento de que estudantes com deficiência são responsabilidade de todos os atores da escola que, juntos, precisam planejar respostas educativas diversificadas para atender às diferentes necessidades pedagógicas. Entretanto, nos parece que esta não tem sido a realidade vivenciada pelos professores de AEE, que relatam resistência às trocas de informação/experiências, por parte de alguns professores:

Eu já tive experiência com professor que a gente trocou informação e já teve outros que não [...]. Teve um professor que eu fui conversar com ele, não era a questão emprestar o material, mas de dar continuidade à estimulação dentro de sala, eu falei que estava trabalhando com o (aluno X) e seria legal que se fosse dar um texto, usar música e cantar, dei uma ideia. Eu acho que seria bacana para o aluno porque estou trabalhando assim com ele. E ela disse: "Ah! Mas eu vou mudar o meu planejamento todo?" E não era nada demais. Aí você percebe que cria uma resistência. Não era nada demais. Era só fazer uma aula com mais movimento, ele (o aluno) ficava lá paradinho (professora S).

Esta fala mostra, com muita clareza, o quanto de culturas, políticas e práticas estão dialética e complexamente imbricadas, cotidianamente. No movimento propositivo da professora encontra-se um tipo de cultura de participação e engajamento com sua função profissional, ao passo que no movimento de resistência do outro professor, uma cultura de separação, desvinculação de funções e não abertura ao diálogo. Nota-se também, na decisão de mudar ou não o planejado, um ato político, pois que certamente orientará a um tipo de prática, e surtirá este mesmo efeito nos alunos envolvidos (e em toda a comunidade, como em um efeito dominó), muito provavelmente. Igualmente, a decisão de propor a mudança traduz um gesto político que, se adotado, acarretaria em outros efeitos na relação com os alunos, a escola, as famílias etc... Por fim, o mesmo ato, cultural e político de se propor algo diferente é, em si mesmo, da dimensão das práticas, as quais também incidirão sobre a comunidade escolar, de algumas maneiras. Tudo isto, em movimentos tanto dialéticos quanto complexos, é uma análise Omnilética vincula- 
da, obviamente, ao ponto de vista das narradoras. Se formos olhar pelo lado do professor resistente, provavelmente levantaremos uma série de outras hipóteses que poderá nos levar por vários outros caminhos, enriquecendo imensamente nossas possibilidades de reflexão-ação. Esta percepção cada vez mais abrangente de uma totalidade (que é sempre provisória) é, também, uma percepção Omnilética.

\section{Considerações Finais}

Propusemo-nos neste artigo relatar o processo de formação continuada sobre inclusão cujo principal foco é deslocar o sentido da deficiência para a potencialidade do estudante em seu processo de aprendizagem. Para atingirmos tal propósito, buscamos compreender o contexto das salas de recursos multifuncionais, em sua dimensão político-pedagógica entrelaçada com a perspectiva omnilética, o que resulta novas e complexas articulações entre o planejamento e a intencionalidade do ato educativo.

Ao utilizarmos as vozes das professoras envolvidas no processo de formação, foi possível evidenciar que um ciclo de formação estruturado omnileticamente pode contribuir em termos de enriquecimento das práticas de planejamento, na medida em que nos coloca em posições de reconsideração dos lugares (simbólicos ou concretos, e sempre temporários) em que estamos, e dos lugares a que queremos chegar, numa postura (culturas) de conexão (práticas) com a incerteza (políticas), com o que ainda não está admitido, mas potencialmente presente (políticas).

O desafio de deslocar sentidos e olhares culturalmente enraizados nos coloca em movimento de mudança e transformação, de não cristalização de nossas culturas, políticas e práticas. Nesta trajetória, também pudemos perceber, ao recorrermos ao objetivo que aqui nos propusemos a alcançar, que o planejamento pedagógico pode beneficiar-se deste olhar omnilético, na medida em que, com o referido olhar, o planejamento torna-se um caminho aberto, não engessado, passível de revisão e mudança, envolvendo, sobretudo, um processo de investigação/ação, que requer a participação dos atores escolares em situações de reflexão e na transformação da realidade da escola, ou seja, no desenvolvimento de estratégias referentes à compreensão crítica da própria prática pedagógica e de seus desdobramentos no processo de participação e de aprendizagem dos estudantes.

Assim, assumimos que a singularidade deste trabalho para o nosso campo de estudo, resulta em afirmar, que o ciclo de formação em questão, colocou todos os atores-participantes-formadores em um movimento de construção-revisão-reconstrução de si mesmos, de seus valores e de suas decisões e ações, tornando-nos mais abertos em relação às contradições e incertezas, a medida que as compreendemos como

$500 \quad$ Educação \& Realidade, Porto Alegre, v. 40, n. 2, p. 485-502, abr./jun. 2015. 
inevitáveis (embora não eternas em si mesmas) e constituintes da própria possibilidade de transformações.

Recebido em 24 de fevereiro de 2014 Aprovado em 14 de setembro de 2014

\section{Nota}

1 Abreviatura para Língua Brasileira de Sinais - Libras.

\section{Referências}

AMORIM, Mariluce da Silva Goulart. Atendimento Educacional Especializado: uma análise sobre as salas de recursos multifuncionais para alunos com surdez. Revista Virtual de Cultura Surda e Diversidade, Petrópolis, n. 8, set. 2011. Disponível em: <http://editora-arara-azul.com.br/novoeaa/revista/?p=636>. Acesso em: 04 fev. 2014.

ANJOS, Hildete Pereira; SILVA, Kátia Regina da; MELO, Luciana Barbosa de. Efeitos da Inclusão nas escolas Públicas: uma leitura a partir de falas de professores e gestores. In: JESUS, Denise Meyrelles de; BAPTISTA, Claudio Roberto; CAIADO, Kátia Regina Moreno. Prática Pedagógica na Educação Especial: multiplicidade do atendimento educacional especializado. Araraquara: Junqueira \& Marin, 2013. P. 63-82.

ARROYO, Miguel Gonzalez. Currículo: território em disputa. Petrópolis: Vozes, 2011

BOOTH, Tony; AINSCOW, Mel. Index Para a Inclusão. Desenvolvendo a Aprendizagem e a Participação na Escola. Rio de Janeiro: UFRJ, 2011.

BOURDIEU, Pierre; PASSERON, Jean Claude. A Reprodução: elementos para uma teoria do sistema de ensino. Petrópolis: Vozes, 2008.

BRASIL. Ministério da Educação. Secretaria de Educação Especial. Política Nacional de Educação Especial na Perspectiva da Educação Inclusiva. Brasília: MEC/SEESP, 2007. Disponível em: <http://portal.mec.gov.br/arquivos/pdf/politicaeducespecial.pdf $>$. Acesso em: 24 mar. 2012.

DAMAZIO, Mirlene Ferreira Machado. Atendimento Educacional Especializado: pessoa com surdez. São Paulo: MEC/SEESP, 2007.

DRAGO, Rogério. Práticas Pedagógicas, Inclusão e Linguagem nos Anos Iniciais do Ensino Fundamental. In: VICTOR, Sônia Lopes; DRAGO, Rogério; PANTALEÃO, Edson. Educação Especial no Cenário Educacional Brasileiro. São Carlos: Pedro \& João Editores, 2013. P. 63-82.

FRANCO, Maria Amélia Santoro. Práticas Pedagógicas nas Múltiplas Redes Educativas. In: LIBÂNEO, José Carlos; ALVES, Nilda (Org.). Temas de Pedagogia: diálogos entre didática e currículo. São Paulo: Cortez, 2012. P. 169-188.

MORIN, Edgard. Introdução ao Pensamento Complexo. Porto Alegre: Sulina, 2006.

PINTO, Umberto de Andrade. A Docência em Contexto e os Impactos das Políticas Públicas em Educação no Campo da Didática. In: LIBÂNEO, José Carlos; ALVES, Nilda (Org.). Temas de Pedagogia: diálogos entre didática e currículo. São Paulo: Cortez, 2012. P. 513-533.

Educação \& Realidade, Porto Alegre, v. 40, n. 2, p. 485-502, abr./jun. 2015. 
ROSENTHAL, Robert; JACOBSON, Lenore. Pygmalion in the Classroom: teacher expectation and student intellectual development. New York: Holt, Rinehart et Winston, 1968.

SANTOS, Mônica Pereira dos. Dialogando sobre Inclusão em Educação: contando casos (e descasos). Curitiba: CRV, 2013.

TROUILLOUC, David; SARRAZIN, Philippe. Les Connaissances Actuelles sur l'Effet Pygmalion: processus, poids et modulateurs. Revue Française de Pédagogie, Lyon, n. 45, p. 89-119, oct./nov./dec. 2003. Disponível em: <http://ife. ens-lyon.fr/publications/edition-electronique/revue-francaise-de-pedagogie/ INRP_RF145_7.pdf>. Acesso em: 15 jan. 2014.

Mylene Cristina Santiago é professora adjunta da Faculdade de Educação da Universidade Federal Fluminense. Vice-coordenadora do Laboratório de Pesquisa, Estudos e Apoio à Participação e à Diversidade em Educação (LaPEADE/UFRJ). Realiza estudos sobre o processo de inclusão e exclusão em educação, formação de professores e interculturalidade.

E-mail: mylenesantiago87@gmail.com

Mônica Pereira dos Santos é professora associada da Faculdade de Educação da Universidade Federal do Rio de Janeiro. Fundadora e Coordenadora do LaPEADE - Laboratório de Pesquisa, Estudos e Apoio à Participação e à Diversidade em Educação (www.lapeade.com.br). Fundadora e Coordenadora da Rede Internacional de pesquisadores em Inclusão em Educação. Representante, no Brasil, da Rede do Index para a Inclusão, da qual é membro, e cuja coordenação internacional cabe do professor Tony Booth, seu fundador.

E-mail:monicapes@gmail.com 